\title{
Post-Neonatal tetanus from broomstick injuries: a word of caution for caregivers
}

\author{
Echey IJEZIE ${ }^{1}$, Fadekemi MEGBELAYIN ${ }^{2}$ \\ ${ }^{1}$ Echey IJEZIE and ${ }^{2}$ Fadekemi MEGBELAYIN, both authors are affiliated with Department of Paediatrics, \\ University of Uyo Teaching Hospital [UUTH], P.M.B 1136, Uyo, Akwa Ibom State, Nigeria.
}

Address for Correspondence: Echey IJEZIE, MBBS, MWACP, FMCPaed., MPH, Department of Paediatrics, University of Uyo Teaching Hospital [UUTH], P.M.B 1136, Uyo, Akwa Ibom State, Nigeria. Email: echeyijezie@yahoo.com; echey4@gmail.com.

\begin{abstract}
Tetanus is a vaccine-preventable disease that is acquired through exposure to the spores of the bacterium Clostridium tetani which are ubiquitous in the soil. Post-neonatal tetanus is an increasing problem in developing countries, including Nigeria. This is mainly as a result of inadequate immunization coverage, unsustainable immunization programmes, and non-administration of booster doses of tetanus toxoid at appropriate periods to eligible children. The spores of the bacterium can get into the body through broken skin, commonly through injuries from contaminated objects. There have also been reports of broomstick injury as the portal of entry. Indeed, it has been reported to be the commonest portal of entry in a center in Nigeria. This is important because flogging (of children) with brooms is common in parts of Nigeria, despite it being forbidden in several cultures in the country. Two cases of post-neonatal tetanus arising from broomstick injuries in Uyo, Nigeria, are herein reported, to illustrate the inherent dangers and implications of broomstick injuries in children. It is hoped that advocacy campaigns will be conducted at different public health fora to raise awareness of the general population concerning post-neonatal tetanus from broomstick injuries. Furthermore, there is urgent need to institutionalize the administration of booster doses of tetanus toxoid at primary and secondary school entry.
\end{abstract}

Key words: Post-Neonatal, Tetanus, Broomstick, Injuries

\section{Introduction}

Tetanus is a vaccine-preventable disease that is acquired through exposure to the spores of the bacterium Clostridium tetani which are ubiquitous in the soil [1]. According to the World Health Organization (WHO), the global figures for tetanus in 2015 indicate that there were 10, 337 reported cases, and 72,600 estimated deaths in $<5$ years (in 2011) [1]. In Nigeria, tetanus accounts for up to $3.7 \%$ of childhood deaths among hospitalized children [2].

Post-neonatal tetanus is an increasing problem in developing countries, including Nigeria $[3,4]$. This is mainly as a result of inadequate immunization coverage, unsustainable immunization programmes, and non-administration of booster

Manuscript received: $20^{\text {th }}$ June 2017

Reviewed: $30^{\text {th }}$ June 2017

Author Corrected: $08^{\text {th }}$ July 2017

Accepted for Publication: 15 $5^{\text {th }}$ July 2017 doses of tetanus toxoid at appropriate periods to eligible children [4].

The spores of the bacterium can get into the body through broken skin, commonly through injuries from contaminated objects [5]. Certain breaches in the skin are more likely to get infected with tetanus bacteria, and these include, wounds contaminated with dirt, faeces, or saliva; puncture wounds, like a nail or needle; burns; crush injuries, and injuries with dead tissue [5].

There have also been reports of broomstick injury as the portal of entry $[4,6,7,8]$. Indeed, it was reported by Ide et al [4] to be the commonest portal of entry in their study. This is important because flogging (of children) with the broom is common in parts of Nigeria, despite it being forbidden in several cultures in the country [8]. 
We herein report two cases of post-neonatal tetanus arising from broomstick injuries in Uyo, Nigeria.

\section{Case Report 1}

A 9-year old girl presented to the Children's Emergency Unit [CHEU] of the University of Uyo Teaching Hospital [UUTH], Uyo, Akwa Ibom State, Nigeria, on the 1st of April, 2017 with a 2week history of broomstick injury to the left arm, fever for 2 days, inability to open the mouth for 2 days, and generalized body spasms for 2 days.

She was in good health until about 2 weeks prior to presentation, when she sustained an injury to her left lower arm, while she was being beaten by her mother using a broom. Broken pieces of the broom got stuck in her left upper arm. She was then taken by her mother to a nearby patent medicine vendor where attempts at removal of the pieces of broomstick were made, but were unsuccessful.

Twelve (12) days after the broomstick injury, she developed spasms which were generalized, frequent and unprovoked. Each episode of spasm lasted for about 5 seconds, and aborted spontaneously, but recurred after every 5-10 minutes. She was then taken to a patent medicine vendor following the spasms, who administered injections on her (the names of the injections are unknown), before referral to UUTH.

Apart from the fact that the mother of the patient did not receive tetanus toxoid injections during the pregnancy for the index patient, other aspects of the history were not contributory. The patient is the 2nd child of 3 children in a monogamous setting. Her mother is a 33-year old fish seller with a primary level of education, while her father is a 34year old fisherman with a secondary level of education. They all live in a 3-room apartment that is well ventilated.

Physical Findings: On physical examination, she was found to be conscious, not dyspnoeic, afebrile with an axillary temperature of $36.6^{\circ} \mathrm{C}$, not pale, not jaundiced, not cyanosed, no signs of dehydration.

Musculoskeletal system: hyper-pigmented healed scars observed on the anterior aspect of the middle $1 / 3$ of the left upper arm with a palpable foreign body in-situ.
Cardiovascular system: Pulse rate: 120/minute, full volume, and regular; BP: 100/50 $\mathrm{mmHg} ; \mathrm{S}_{1}, \mathrm{~S}_{2}$ only. No murmurs.

Respiratory system: Respiratory rate: 33/min; Central trachea, normal chest and bilaterally symmetrical chest expansion. Globally resonant percussion notes. The breath sounds were vesicular.

Digestive system: good oral hygiene, moist buccal mucosa, no thrush. Abdomen: flat, and moved with respiration, with board-like rigidity; the liver was not palpable; the spleen was not palpable and the kidneys were not ballotable. The bowel sounds were normal.

Central nervous system: Conscious with a Glasgow Coma Scale of 15/15. No signs of meningeal irritation; No other abnormality detected.

Diagnosis: Generalized Tetanus (Tetanus Score [Dakar] of 3; Incubation period: 12 days; Period of onset: less than 24 hours).

She was managed in a dark, quiet room and received intramuscular anti-tetanus serum 10,000 I.U. stat. She was also given intravenous antibiotics: ceftriaxone and metronidazole. A cocktail of alternating doses of sedatives and anticonvulsants were administered to her, and these included phenobarbitone, chlorpromazine and diazepam.

Wound exploration was performed by the plastic surgeons and revealed a $4.5 \mathrm{~cm}$ long piece of broomstick. She clinically improved and was discharged after 35 days of hospital admission, and received intramuscular tetanus toxoid injection at discharge. Her caregivers were also adequately counselled.

\section{Case Report 2}

A 15-year old boy presented to the Children's Emergency Unit [CHEU] of the University of Uyo Teaching Hospital [UUTH], Uyo, Akwa Ibom State, Nigeria, on the 24th of April, 2017 with a 2week history of broomstick injury to the left arm, fever for 3 days, inability to open the mouth for 2 days, and generalized body spasms for 1 day. 
He was in good health until about 2 weeks prior to presentation, when he sustained an injury to his left lower arm, while he was being beaten by his cousin using a broom. Broken pieces of the broom got stuck in his left lower arm. Attempts were made at home to remove the pieces of broomstick stuck in his arm but were unsuccessful.

Eleven (11) days after the broomstick injury, he developed high grade, continuous fever.

Two (2) days prior to presentation at UUTH, he was unable to open his mouth, and subsequently developed generalized body spasms which were both provoked and unprovoked. Each episode of spasm lasted for about 15 seconds and stopped spontaneously.

On account of the frequent body spasms, he was taken to a patent medicine vendor, from where he was referred to UUTH. He had not received any tetanus booster dose prior to presentation.

The patient is the 1 st child of 2 children of the parents. Both parents are dead, and he lives with his maternal grandmother, who is a petty trader. Other aspects of the history were not contributory.

Physical Findings: On physical examination, he was found to be conscious with a Glasgow Coma Scale of $15 / 15$, not dyspnoeic, febrile with an axillary temperature of $38.5^{\circ} \mathrm{C}$, not pale, not jaundiced, not cyanosed, no signs of dehydration, had unprovoked spasms and nuchal rigidity.

Musculoskeletal system: bulbous, hyperpigmented, firm swelling on the ulnar part of the inferior aspect of the forearm.

Cardiovascular system: Pulse rate: 100/minute, full volume, and regular; BP: 90/60 $\mathrm{mmHg} ; \mathrm{S}_{1}, \mathrm{~S}_{2}$ only. No murmurs.

Respiratory system: Respiratory rate: 30/min; Central trachea, normal chest and bilaterally symmetrical chest expansion. Globally resonant percussion notes. The breath sounds were vesicular.

Digestive system: good oral hygiene, moist buccal mucosa, no thrush. Abdomen: flat, and moved with respiration, with board-like rigidity; No organs were palpably enlarged. The bowel sounds were normal.

Central nervous system: Conscious with a Glasgow Coma Scale of 15/15. Nuchal rigidity; No other abnormality detected.

Diagnosis: Generalized Tetanus (Tetanus Score [Dakar] of 3; Incubation period: 12 days; Period of onset: 24 hours).

He was managed in a dark, quiet room, and received intramuscular anti-tetanus serum 10,000 I.U. stat. He was also given intravenous antibiotics: cefuroxime and metronidazole. A cocktail of alternating doses of sedatives and anticonvulsants were administered to him, and these included phenobarbitone, chlorpromazine and diazepam.

Wound exploration was performed by the plastic surgeons and revealed a piece of broomstick with surrounding pus.

While on admission, he developed respiratory distress and bedsores which were successfully managed. He also received physiotherapy. He clinically improved and was discharged after 49 days of hospital admission, and received intramuscular tetanus toxoid injection at discharge. His caregivers were also adequately counselled.

\section{Discussion}

Tetanus is a significant cause of morbidity and mortality in developing countries [3,9], and is a public health problem in Nigeria [9], with case fatality rates as high as $4.1 \%-39.1 \%$ [2-4,10-13].

Generalized tetanus is the most common form of tetanus. It accounts for more than $80 \%$ of cases [14]. The most common initial sign is the spasm of the muscles of the jaw or "lockjaw" is the most common initial clinical sign. This may be followed by painful spasms in other muscle groups in the neck, trunk, and extremities and in severe cases, by generalized, seizure-like activity or convulsions [14]. The "lockjaw" and spasms (provoked and unprovoked) were present in the two cases presented in this report.

In some centres in Nigeria, post-neonatal tetanus accounts for up to $1.4 \%$ (of paediatric admissions) and to $2.7 \%$ of post-neonatal hospital admissions 
$[3,9]$. In addition to the attendant morbidity, hospitalization as a result of post-neonatal tetanus can last for several weeks with significant financial cost to the family, and absenteeism from school for the affected children [2,8]. The patients herein reported spent 35 and 49 days (case 1 and case 2 respectively) in UUTH. This is similar to the findings by other authors $[3,4,9,13]$.

Different portals of entry of the spores of the causative organism have been described: wounds contaminated with dirt, faeces, or saliva; puncture wounds, like a nail or needle; burns; crush injuries, and injuries with dead tissue [5].

Additionally, broomstick injuries have been noted to constitute a significant cause of tetanus in children in Nigeria $[4,6,8]$. This was so with the two cases presented in this report. This scenario (flogging of children with brooms) exists despite it being forbidden in several cultures in the country [8]. Indeed, in a study by Mahmoud et al.,[15] to document the observations of elementary school teachers in Ilorin, Nigeria, on their practice of some types of corporal punishment that could result in eye injuries among their pupils, $32(18.6 \%)$ of the teachers had observed the broom as the item being used to dispense corporal punishment to erring pupils [15].

The two cases herein reported occurred in the same month (April 2017) and within the same geographical area.

These were clearly avoidable and can be termed as a form of child abuse.

It is therefore important that parents/caregivers (and school teachers) should be enlightened on the dangers of using brooms to reprimand erring children.

It is hoped that advocacy campaigns would be conducted at different public health fora to raise awareness of the general population concerning post-neonatal tetanus from broomstick injuries.

\section{Conclusion}

Post-neonatal tetanus is a significant public health challenge in Nigeria that can result in prolonged hospital admission, with a high financial cost to the family, and absenteeism from school for the affected children. It can arise from broomstick injuries, amongst other portals of entry of the spores of the causative organism. These broomstick injuries are avoidable.

This case report adds to the existing knowledge of tetanus by highlighting its occurrence from broomstick injuries in this locality, from where it has not been previously reported. There is need to enlighten the general public about the dangers of reprimanding children with brooms.

Furthermore, there is urgent need to institutionalize the administration of booster doses of tetanus toxoid at primary and secondary school entry as recommended by several authors [9, 10,12].

Funding: Nil, Conflict of interest: None

Permission of IRB: Not required

\section{References}

1. World Health Organization (WHO). Tetanus. Availablefrom:http://www.who.int/immunization/ monitoring_surveillance/burden/vpd/surveillance_t ype/passive/tetanus/en/. 2017; Accessed: 08.07.2017.

2. Animashaun BA, Gbelee $\mathrm{OH}$, Ogunlana AT, Njokanma OF, Odusanya O. Profile and outcome of patients with post-neonatal tetanus in a tertiary centre in south west Nigeria: any remarkable reduction in the scourge? Pan African Medical Journal. 2015; 21:254. DOI:10.11604/pamj.2015.21.254.

3. Oyedeji OA, Fadero F, Joel-Medewase V, Elemile P, Oyedeji GA. Trends in neonatal and post-neonatal tetanus admissions at a Nigerian teaching hospital. J Infect Dev Ctries. 2012; 6(12):847-853. Available: https://jidc.org/index.php/journal/article/download/ 23276738/802/.

4. Ide LEY, Uchenwa-Onyenegecha TA. Post Neonatal Tetanus: 20 Years Experience as Seen at the University of Port Harcourt Teaching Hospital. British Journal of Medicine \& Medical Research. 2016; $12(2)$ : $1-5$ DOI: 10.9734/BJMMR/2016/19047.

5. Centers for Disease Control and Prevention (CDC). Tetanus: Causes and Transmission. 2017; Availablefrom:https:/www.cdc.gov/tetanus/about/c auses-transmission.html. Accessed: 08.07.2017. 


\section{Case Report}

6. Ejike O, Chapp J, Onyire B, Amadi AN. Pattern And Outcome Of Childhood Tetanus In Aba. Journal of Medical Investigation and Practice.2003;(4):19-22. Available from: https://www.ajol.info/index.php/jomip/article/view/ 29010.

7. Talabi OA, Aigoro NO, Oyedeko MO, Akinbode RS, Salaudeen LK. Recurrent Local Tetanus: A Case Report. Nigerian Medical Practitioner. 2004;46(1):2 - 3.

8. Eberechukwu YIL, Angela B-ON. The SocioEconomic Challenges in Post Neonatal Tetanus. Modern Economy. 2015;(6):1327-1332. Available from: http://dx.doi.org/10.4236/me.2015.612125.

9. Alhaji MA, Akuhwa RT, Mustapha MG, Ashir GM, Mava Y, Elechi HA, Bukar FL. Post-neonatal tetanus in University of Maiduguri Teaching Hospital, North-eastern Nigeria. Niger J Paed. 2013;40(2): $\quad 154-157 . \quad$ DOI: http://dx.doi.org/10.4314/njp.v40i2,9.

10. Fatunde OJ, Familusi JB. Post Neo-Natal Tetanus in Nigeria: A Need for Booster Doses of Tetanus Toxoid. Nigeria Journal of Paediatrics.2001;28(2):38-38. Available: https://www.ajol.info/index.php/njp/article/view/ 12053.DOI:http://dx.doi.org/10.4314/njp.v28i2.120 53.

11. Anah MU, Etuk IS, Ikpeme OE, Ntia HU, Ineji EO, Archibong RB. Post Neonatal Tetanus in
Calabar, Nigeria: A 10 Year Review. Nigerian Medical Practitioner. 2008;54(2):45-47. Online, available:https://www.ajol.info/index.php/nmp/arti cle/view/28947.DOI:http://dx.doi.org/10.4314/nmp .v54i2.28947.

12. Emodi IJ, Ikefuna AN, Obichukwu C. Incidence and outcome of neonatal tetanus in Enugu over a 10-year period. South African Journal of Child Health. 2011;5(4):117. DOI:10.7196/SAJCH.373.

13. Chukwuka JO, Ezeudu CE, Nnamani KO. Neonatal and Post-Neonatal Tetanus in Nnamdi Azikiwe University Teaching Hospital, Nnewi, South-East, Nigeria: A 10-year review. Trop J Med Res. 2015 Jan - Jun;18 (1):30-33. DOI: 10.4103/1119-0388.152552.

14. Centers for Disease Control and Prevention (CDC). Tetanus: Symptoms and Diagnosis. 2017; Online,available:https://www.cdc.gov/tetanus/clini cians.html.

15. Mahmoud AO, Ayanniyi AA, Salman MF. Observations of teachers in llorin, Nigeria on their practices of corporal punishment that are potentially injurious to their pupils' eyes. Annals of African Medicine. 2011 April-June;10(2):150-154. Availablefrom:http://www.bioline.org.br/request?a m11030. DOI: 10.4103/1596-35.19.82075.

\section{How to cite this article?}

Echey IJEZIE, Fadekemi MEGBELAYIN Post-Neonatal tetanus from broomstick injuries: a word of caution for caregivers. Int J Med Res Rev 2017;5(07):644-648. doi:10.17511/ijmrr. 2017.i07.01. 